Dr. Ulbrich \& Kaminski

Rechtsanwälte I Notar (Hrsg.)

\title{
Heim-Management in der Coronakrise
}

Der Rechtsratgeber

\section{Autorinnen und Autoren}

Ralf Kaminski

Jan Pakirnus

Eileen Kemnitz

Svenja Foss

Steffen Ebert

Dr. Stefan Ulbrich

Alexandra von Hobe 


\section{Bibliografische Information der Deutschen Nationalbibliothek}

Die Deutsche Bibliothek verzeichnet diese Publikation in der Deutschen Nationalbibliografie; detaillierte bibliografische Daten sind im Internet über http://dnb.d-nb.de abrufbar.

Sämtliche Angaben und Darstellungen in diesem Buch entsprechen dem aktuellen Stand des Wissens und sind bestmöglich aufbereitet.

Der Verlag und der Autor können jedoch trotzdem keine Haftung für Schäden übernehmen, die im Zusammenhang mit Inhalten dieses Buches entstehen.

\section{(c) VINCENTZ NETWORK, Hannover 2020}

Besuchen Sie uns im Internet: www.altenheim.net

Das Werk ist urheberrechtlich geschützt. Jede Verwendung außerhalb der engen Grenzen des Urheberrechtsgesetzes ist ohne Zustimmung des Verlages unzulässig und strafbar. Dies gilt insbesondere für die Vervielfältigungen, Übersetzungen, Mikroverfilmungen und Einspeicherung und Verarbeitung in elektronischen Systemen.

Die Wiedergabe von Gebrauchsnamen, Warenbezeichnungen und Handelsnamen in diesem Buch berechtigt nicht zu der Annahme, dass solche Namen ohne Weiteres von jedermann benutzt werden dürfen. Vielmehr handelt es sich häufig um geschützte, eingetragene Warenzeichen.

\section{Druck: SDK Systemdruck Köln}

Foto Titelseite: AA+W - AdobeStock 
Dr. Ulbrich \& Kaminski

Rechtsanwälte I Notar (Hrsg.)

\section{Heim-Management in der Coronakrise}

Der Rechtsratgeber 